\title{
Refractory Stage 0 Bladder Cancer AJCC v6 and $v 7$
}

National Cancer Institute

\section{Source}

National Cancer Institute. Refractory Stage O Bladder Cancer AJCC v6 and v7. NCI

Thesaurus. Code C148286.

Stage 0 bladder cancer defined according to the AJCC v6 and v7 criteria that is resistant to treatment. 